\title{
Research on the Role of Ideological and Political Education in the Cultivation of College Students' Professional Qualities in the New Situation
}

\section{Ruoyang Li}

Shanghai University of Medicine \& Health Sciences, 279 ZhouZhu Road, Shanghai, China

\section{Abstract}

Medicine is an ever-changing subject, its generations of successors have grown up continuously in training. The professional quality of medical students involves their learning attitudes and learning effects, and even the direction and sublimation of future careers. The ideological and political education in colleges and universities should aim at cultivating students' professional quality, promote the development

Corresponding Author:

Ruoyang Li

liry@sumhs.edu.cn

Received: 29 August 2018

Accepted: 18 September 2018

Published: 11 November 2018

Publishing services provided by Knowledge $\mathrm{E}$

(c) Ruoyang Li. This article is distributed under the terms of the Creative Commons

Attribution License, which permits unrestricted use and redistribution provided that the original author and source are credited.

Selection and Peer-review under the responsibility of the ICOI-2018 Conference Committee.

\section{G OPEN ACCESS} of human resources and play an important role in the realization of a strong human resource, must start from the ideals and beliefs education, moral quality education, professionalism education, innovative spirit education, service awareness education, career outlook education and other aspects to enhance the adaptability and competitiveness of higher education.

Keywords: ideological, political, professional quality, cultivation

\section{Introduction}

\subsection{The significance of medical college students' professional quality}

Most experts and scholars have very different interpretations on medical college students' professional qualities. Scholars generally believe that professional quality is the human need to abide by the code of conduct in the social activities, it includes professional interest, professional capacity, professional personality and professional situation, and many other aspects [1]. In recent years, the "Undergraduate Medical Education Standards - Clinical Medicine (Trial)" issued jointly by the Ministry of Education and the Ministry of Health of China considers, the professional qualities of medical students should meet the following requirements: Cherish every life, have a high sense of responsibility, and have a correct attitude to respect every patient who comes 
to consult; Show appropriate attitude and patience to the patient's extreme family; Recognize and correctly handle medical negligence. Medical students' professional quality is the basic knowledge and professional knowledge, clinical skills, humane care, teamwork, professionalism, humanistic quality, and scientific spirit that medical students need to adapt to the medical industry [2]

\section{Why Cultivate the Professional Quality of Medical College Students?}

\subsection{Strengthening the professional quality of medical students is an inevitable requirement for adapting to social development}

The knowledge and skills required by the profession of doctor are constantly developing and changing. Only through continuous learning we can acquire new theories, technologies and methods. Cultivating the professional quality of medical students is to improve the students' ability to continuously learn and adapt to the development of the society, not to limit the existing knowledge and ability [3]. Super medical technology and high quality of medical ethics are not innate, but rely on continuous cultivation and training in the acquired practice [4]. With the rapid development of society, a medical student should be able to keep pace with the times, master new knowledge and technology through continuous learning, and meet the needs of the society and the people.

\subsection{Every medical student must have a good professional quality}

In modern society, every medical student should have a good professional quality, which also affects the future of each doctor [5]. Having a good work ethic not only enables them to face up to their shortcomings, but also enables them to find their own advantages. Students according to their own situation to determine their future development, through the constantly study hard to improve their cultural level, to learn advanced knowledge of medical frontier, improve clinical skills, make oneself of the mind and body get all-round development. Medical students cultivate a good professional quality, clear their own responsibilities and obligations, and maintain a positive attitude in terms of their outlook on life, values, and career perspectives, so that they can be dedicated, honest, trustworthy and united in their work [6]. 


\subsection{Cultivating medical students' professional qualities is the need of adapting to employment}

Choosing medicine is not only the determination of students' future development direction, but also the purpose of improving their family's economic status. Facing the increasingly severe employment situation, finding one ideal job is the common expectation of students and parents. Faced with fierce employment competition, on the one hand, schools are required to provide vocational training for students and improve the competitiveness of students' employment; on the other hand, students are required to study hard, master knowledge and skills, and enhance their own strength. Through joint efforts of both parties to help students adapt to the successful employment of the society, the university students will complete the transition from students to professionals and become a doctor with excellent professional qualities.

\section{Taking the "Strengthen Moral Education and Core Values Education" As the Starting Point, Do a Good Job As the Student's Mentors and Guides}

The origin of education is the cultivation of people [7-8]. The origin of ideological and political education work is "strengthen moral education and cultivate people". Moral character comes first in educating people. Today, in the context of the great social change, it is particularly urgent to emphasize the importance of cultivating moral characters. In his famous essay "education for cultivating independent thinking", Einstein warned that "It is not enough to educate people with professional knowledge. Through professional education, he can become a useful machine, but he cannot become a person who develops harmoniously. ... He - together with his expertise - is like a well-trained dog, not a harmonious person ". This is said to the educated, but also to the education workers, such views deserve our deep consideration. Therefore, in the process of university education and management, teachers and ideological and political workers should work hard to transport qualified college students for society.

To teach and educate people, we must first have noble teacher ethics [9]. Teacher's morality is like the life of a teacher, it is the foundation of teachers and education. The mission of medical colleges and universities is to train high-quality medical workers for the country and society who are high quality comprehensive talents that integrates scientific and medical professional knowledge and practice, moral cultivation and professional quality, physical and mental quality and humanistic quality. As teachers and 
ideological and political education workers in medical colleges, they have the social responsibility and social mission to educate and train high-quality comprehensive talents for the country and society.

\section{To Promote the Ideological Quality of College Students}

\subsection{Combine in-class and out-of-class}

We will fully implement online education in each school, integrate the needs of each student, regard professional quality as a breakthrough in social education, and strive to solve the difficulties and pressures faced by each student. We should give full play to the role of ideological and political courses, use the form of group discussion to understand each student's ideological situation and difficulties, and use the school's website, Weibo or WeChat platform. Guide students in the cyberspace to carry out interactive discussions on career planning and growth needs, conduct timely communication and service with counselors and ideological and political teachers in various schools, and answer student concerns and questions efficiently and conveniently. We could set up a network consulting studio, keep close to the professional quality of doctors, and guide students to establish correct professional ethics and values in a way that students are happy to hear.

\subsection{Promote in-class and out-of-class integration}

Classroom education is always an important part of the school and extracurricular education is equally important. First, we should fully mobilize the enthusiasm of teachers, integrate professional quality education into extra-curricular activities, formulate the "Measures for Cultivating Teacher Education," and "Measures for Incentive Training for Teacher Education," and other documents that quantify professional teachers' participation in extracurricular education and serve as a prerequisite for the promotion of titles. In addition, we should fully stimulate students' enthusiasm, student affairs office, office and other departments jointly launched the "certificate of college students' comprehensive quality education system and standardize management of the certification of all kinds of extracurricular education. What's more, we should fully activate the carrier's vitality, use the second classroom to extend professional education, and closely combine professional characteristics to design medical skills competitions, professional internships, social practices, and industry expert lectures. 


\section{Measures to Improve the Development of Medical Students' Professional Quality}

\subsection{Improve practical courses and consider all aspects of professional accomplishment}

From the perspective of psychology, internal motivation is a key factor in the development of medical students' professional quality [10]. Therefore, the improvement of medical students' self-cognition is beneficial to the motivation of medical production students and the self-consciousness of improving their professional quality. It is especially important to improve the practical courses and strengthen the training of professional quality. We can start from the following three aspects: First, students need to fully understand what professional qualities are. Only by understanding its connotation can students consciously improve their own quality; Second, it is important to emphasize that all aspects of medical students' professional qualities are equally important. In view of the medical students more pay attention to professional knowledge learning and unaware of the professional quality are as important as other ways, therefore, teachers should consciously to show all aspects of the professional quality, emphasizes the importance of relevant content during their teaching process. At the same time, medical colleges may also appropriately increase related compulsory and elective courses. For example, the course system of "the heart of the healer" established and implemented by our school, effectively promotes students' professional quality training and achieves comprehensive development; Third, we should strictly check the professional qualities of teachers. Clinical doctors consciously integrate humanistic care and other content into teaching, and sets a good example is more subtle and effective than simple classroom teaching. Therefore, medical colleges and universities should regularly evaluate the teaching level and professional quality of teachers to ensure the quality of teaching.

\subsection{Strengthen medical ethics education and cultivate team spirit}

The cultivation of medical ethics and team spirit is conducive to the self-improvement of medical students. From the results of questionnaires and interviews, most students in our college are determined to be medically committed and pay attention to the care of patients. However, some students still do not insist on respecting and caring for patients during the intern process. Therefore, we can learn from other medical colleges and universities in China, improve the medical ethics of our students and 
promote their active thinking by conducting courses such as ethical discussion. In addition, we have made three suggestions to further strengthen the cultivation of student team consciousness. First, teachers should infiltrate the cultivation of team spirit into teaching activities, such as encouraging group discussion in class; Second, students should conduct teaching activities in group mode, stipulate that students should take group as the unit for internship, and this is effectively cultivate students' sense of teamwork; Third, schools should encourage students to participate in team activities, use of college exchanges, skills competitions and other methods to cultivate students' team awareness.

\subsection{Pay attention to science education and improve self-learning ability}

Lifelong learning is a kind of ability and attitude, this ability is due to education's emphasis on the scientific spirit. To improve students' ability to learn autonomously in scientific practice, based on the following points. First, we can start from the classroom, diversify the forms of classes, popularize heuristics, interactive and inquirybased teaching models, and encourage students to express their own ideas. For example, an effective PBL course can, to a certain degree, improve students' ability to learn independently and their desire for knowledge. Universities that have conducted PBL education should continuously improve the PBL teaching system according to the actual situation of students. While hiring teachers with a high level of professional knowledge, colleges should also pay attention to its organization guidance ability and richness of comprehensive knowledge and develop qualified PBL teachers. Secondly, in extracurricular activities, we will carry out activities centering on scientific and technological innovation topics. Through the creation of more scientific practice opportunities, we cultivate students' scientific spirit, innovation, criticism and other scientific spirits. Finally, in some large-scale activities, students are encouraged to participate and reward students who have achieved outstanding results to obtain a catalytic effect and enhance their scientific exploration spirit. Medicine is an ever-changing subject, its generations of successors have grown up continuously in training. The professional quality of medical students involves their learning attitudes and learning effects, and even the direction and sublimation of future careers. 


\section{Conclusion}

Modern society has higher requirements for technical talents, especially higher medical universities are more critical for the selection of talents. Therefore, we need to improve the professional quality of doctors, so that they have higher skills and higher professional ethics. Improve the professional ethics of doctors is a key education content of each university. The work of ideological and political education makes their behavior consistent with their demonstrated qualities, this will also play a solid foundation for their future and achieve the final success of their career.

\section{References}

[1] Chen Jinmei. (2015) Investigation and Analysis on the Cognitive Status of Medical Students' Professional Quality. China Higher Medical Education, 8, 35-35.

[2] Liu Fang, Dai Anqiong. (2012) Analysis of ways to strengthen medical students' professional quality education. Chinese Health Service Management, 29(2), 143144.

[3] Chen Yumin, Li Yu, Zhang Lingen. (2009) Exploration of Vocational Education for Clinical Medical Students. China Higher Medical Education, 3, 23-25.

[4] Chakarova, I., Delimitreva, S., Hadzhinesheva, V., Zhivkova, R., Nikolova, V., Dimitrov, R., \& Markova, M. (2016). Correlation between defects of chromatin condensation and spindle assembly in oocytes of two mouse strains. Comptes rendus de l'Académie bulgare des Sciences, 69(9).

[5] Wang Chunguang. (2007) Thinking on Strengthening Medical Students' Professional Spirit Education. Chinese Medical Ethics, 20(2), 26-28.

[6] Hadzhinesheva, V., Delimitreva, S., Markova, M., Nikolova, V., Chakarova, I., Mourdjeva, M., \& Zhivkova, R. (2017). Localization and asymmetric distribution of golgi complex and fibrillar actin in oocytes from newborn mouse ovaria. Comptes rendus de l'Académie bulgare des Sciences, 70(7).

[7] Ma Juhua, Yan Shirong, Wang Huosong. (2012) Research on the Cultivation and Evaluation Model of Medical Students' Professional Spirit. Chinese Medical Ethics, 25(2), 259-261.

[8] Liu Zhifei, Ma Xiaodan, Wen Deliang. (2010) An analysis on how to cultivate medical students' professionalism in medical colleges and universities. Chinese Medical Ethics, 23(6), 60-62. 
[9] Chavdarov, I. N. (2017). Functional and structural diversity of a walking robot with a manipulator. Comptes rendus de l'Académie bulgare des Sciences, 70(5). 